\title{
Antecedentes de la legislación cooperativa costarricense
}

\author{
Roxana Sánchez Boza \\ Universidad Nacional de San José. Costa Rica
}

Recibido: $\quad 15.06 .09$

Aceptado: 8.07 .09

Sumario: 1. Iniciativas de reforma parcial a la legislación cooperativa, - 2. Iniciativas que reforman indirectamente la legislación y la vida del cooperativismo nacional,-3. La necesaria reforma a la Ley de organizaciones cooperativas, - 4. La Ley Marco para las cooperativas de América y nuestras propuestas de reforma al marco jurídico cooperativo de Costa Rica.

Resumen: Es de importancia destacar el contexto en el que nace la primera normativa para cooperativas en Costa Rica, en tanto que este país se abrió a las propuestas del Partido Comunista y de la Iglesia Católica, al gobierno demócrata cristiano del Dr. Rafael Angel Guardia, quien ese momento estuvo de acuerdo en modificar la Constitución Política e introducir un Capítulo de Garantías Sociales y promulgar un Código de Trabajo.

Palabras clave: cooperativismo costarricense, orígenes, garantías sociales.

Abstract: It is important to highlight the context in which the first regulations for cooperatives in Costa Rica were created. This country adopted proposals from the Communist Party and the Catholic Church, with the Christian Democrat government led by Dr. Rafael Angel Guardia, who, at the time, agreed to modify the Political Constitution and include a chapter on Social Guarantees and enact a Labour Code.

Key words: cooperativism in Costa Rica, origins, social guarantees. 
De importancia es destacar el contexto en que nace la primera normativa para cooperativas, en Costa Rica, en el tanto que este país se abrió a las propuestas del Partido Comunista y de la Iglesia Católica, al gobierno demócrata cristiano del Dr. Rafael Angel Guardia, quien ese momento estuvo de acuerdo en modificar la Constitución Política e introducir un Capítulo de Garantías Sociales y promulgar un Código de Trabajo, realmente protector.

En la Constitución Política de 1949 se introduce el artículo 64 que abriga en forma concreta a las cooperativas y el artículo 74 como norma general de interpretación de la normativa social de ese cuerpo normativo.

Por ley N. ${ }^{\circ} 4179$ promulgada el 28 de agosto de 1968, se independiza la legislación cooperativa, de la legislación laboral del Código de Trabajo.

Cinco años más tarde, se promulgó la Ley N. ${ }^{\circ} 5185$, de 20 de febrero de 1973, como una modificación sustancial a la Ley N. ${ }^{\circ} 4179$, al dar origen a dos entidades trascendentales en el desarrollo histórico del movimiento cooperativo; el Instituto Nacional de Fomento Cooperativo y el Consejo Nacional de Cooperativas.

Y a más de una década, la Ley N. ${ }^{\circ} 6756$, de 5 de mayo de 1982, incorpora a la legislación cooperativa el capítulo correspondiente a las cooperativas de autogestión y los organismos auxiliares.

Esa reforma sustancial introduce un importante capítulo a la ley de asociaciones cooperativas, en el cual se contempla dos modelos de acceso a la propiedad dentro de las cooperativas. Es en 1982, donde surgen las cooperativas autogestionarias y cogestionarias, contando como antecedente inmediato la circulación en el ámbito legislativo de un proyecto de ley con pretensiones de dar mayor soporte legal y material por los beneficios que se introducían, a las empresas comunitarias campesinas.

Por supuesto, que el antecedente de la reforma de 1982 tiñó la naturaleza de ese tipo de cooperativas por muchos años, hasta el punto de encontrarnos que muchos funcionarios públicos del sector cooperativo, rechazaban de plano el nacimiento de cualquier cooperativa, sobre todo bajo el modelo autogestionario, con miembros profesionales o titulares de medios de producción. Ejemplo vivo para la autora fue mi participación en el primera cooperativa autogestionaria de abogados, en el año 1983 y la lucha por su autorización para funcionar, contra funcionarios del Instituto nacional de fomento cooperativo; contra la Comisión de Cooperativas Autogestionarias, creada por esa reforma, los abogados del Movimiento Cooperativo — quienes veían como amenaza que 12 jóvenes abogados y abogadas incursionaran en el Movimiento Cooperativo, en ese rumbo- y hasta en el mismo Colegio de Abogados, por consideraban que les habíamos quitado el nombre elegido por la Junta 
Directiva para crear su propia cooperativa de ahorro y préstamo, en el tanto que habíamos decidido llamarnos COOPEABOGADOS R.L.

En 1982 asumió la Presidencia de la República, Luis Alberto Monge, socialdemócrata con vena cooperativista y promulgó cerca de 40 leyes, de la cuales la mayoría fueron para dotar de recursos económicos al Movimiento Cooperativo nacional.

Una década más tarde, frente a la revisión de las exoneraciones existentes en aquél momento en el ordenamiento jurídico costarricense, se comprobó que había un exceso y el fisco estaba bien afectado, de tal modo que se dio la una ley que eliminó incentivos y exoneraciones a favor de múltiples actividades y grupos de interés, con graves efectos en el amplio artículo 6 de la Ley de asociaciones cooperativas, el cual sufrió una importante reducción en su contenido y trajo abajo muchas de las luchas del Movimiento Cooperativo, plasmadas en incentivos para participar en este sector de la economía social.

Del año 1982 al presente, el Movimiento Cooperativo ha elaborado múltiples propuestas de reforma a la legislación cooperativa, sin éxito alguno. La última y más importante fue presentada en el año 2003 a la Asamblea Legislativa y tuvo avances significativos en su estudio y análisis por parte de la Comisión de Asuntos Jurídicos, en donde se recibieron dictámenes de mayoría a favor de su reformas y de minoría en contra de los mismos, pero coincidió con año electoral y quedo durmiendo el sueño de los justos.

Actualmente, nos encontramos que ni las propuestas de la Organización de Cooperativas de América, OCA, con sede en Colombia, que impulsó la ley Marco para cooperativas de América, ni la Recomendación 193 de 2002 de la OIT sobre la Promoción de las Cooperativas', ni la iniciativa de revisión de esa propuesta, impulsada por la Alianza Internacional Cooperativa para América, del año 2005, han promovido más iniciativas para fortalecer a las cooperativas mediante una legislación más acorde al desarrollo de las entidades de economía social, en el país y en el resto del mundo.

\footnotetext{
1 Una cooperativa es una «asociación autónoma de personas que se han unido de forma voluntaria para satisfacer sus necesidades y aspiraciones económicas, sociales y culturales en común mediante una empresa de propiedad conjunta y de gestión democrática». (R193 OIT, art. 2). Los principios cooperativos son: "adhesión voluntaria y abierta; gestión democrática por parte de los socios; participación económica de los socios; autonomía e independencia; educación, formación e información; cooperación entre cooperativas, e interés por la comunidad» (R193 OIT, art. 3 (b)). Los valores cooperativos son: «autoayuda, responsabilidad personal, democracia, igualdad, equidad y solidaridad, y una ética fundada en la honestidad, transparencia, responsabilidad social e interés por los demás» (R 193 OIT, art 3 (a).
} 


\section{Iniciativas de reforma parcial a la legislación cooperativa}

Durante los últimos 10 años se ha presentado varias propuestas de reformas a la Ley de Asociaciones cooperativas, producto a veces de la misma lucha de intereses de los diversos componentes del Movimiento Cooperativo, el cual sabemos no es homogéneo en su integración - cooperativas fuertes económicamente frente a pequeñas y con poco sustento económico; líderes que participan en los entes cooperativos de decisión político-económica- o bien, del mismo Estado interesado en atraer más y más recursos a sus arcas centrales.

Hacemos un recuento de las propuestas legislativas y el estado en la corriente legislativa:

\subsection{Reforma parcial a la LAC para el fortalecimiento del sector} cooperativo de ahorro y crédito, expediente legislativo N. 17.187 presentado por el diputado Joaquín Salazar Rojas, octubre 2008

El fondo de la reforma consiste en introducir en el artículo 139 de la LAC, la asamblea de cooperativas de ahorro y crédito para asegurar la participación en 10 puestos en propiedad y 3 suplencias en el órgano máximo del Movimiento Cooperativo denominado PLENARIO DEL CONSEJO NACIONAL DE COOPERATIVAS.

El fundamento se encuentra en la amplia participación de ese sector de cooperativas dentro del Cooperativismo nacional, con datos al año 2008 en cuanto a su Considerando que el sector de ahorro y crédito cooperativo costarricense atiende a más del 14\% del total de la población económicamente activa del país y que anualmente moviliza más de 300 mil millones de colones de crédito, casi 200 mil millones de ahorro de una clase muy popular de nuestra población y valorando la gran contribución que realiza anualmente al desarrollo de iniciativas crediticias orientadas a la vivienda de clase media-baja y baja-baja cercana a las 1.600 soluciones anuales, se justifica social y económicamente la identificación de esta clasificación funcional y jurídica de cooperativa como grupo formal dentro del concepto de tipo de cooperativas y sector específico dentro de la ley. ${ }^{2}$

2 Datos incluidos en la exposición de motivos de la reforma comentada, p.1. Este proyecto pasó a estudio e informe de la Comisión Permanente de Asuntos Sociales de la Asamblea Legislativa. 


\subsection{Propuesta de una interpretación auténtica del artículo 80 de la} LAC., expediente N. 17.156, ST.325-2008 J, noviembre 20083, diputado Oscar Nuñez, con revisión y autorización final

El proyecto perseguía aclarar a cuál ente beneficia el artículo 80 actual de la Ley de Asociaciones Cooperativas y Creación del Instituto Nacional de Fomento Cooperativo: al CENECOOP como parte del Instituto Nacional de Fomento Cooperativo ( INFOCOOP) o bien, al ente privado llamado Cenecoop R.L.

Dice así ese artículo 80, primer párrafo, de la Ley N. ${ }^{\circ} 4179$ :

«ARTÍCULO 80.- Los excedentes deberán destinarse, por su orden, para constituir las reservas legales, la reserva de educación, la reserva de bienestar social y cualesquiera otras reservas establecidas en los estatutos; para cubrir las obligaciones provenientes de las cuotas de inversión; para pagar al CONACOOP el dos por ciento (2\%) de los excedentes, conforme con lo estipulado en el artículo 136 de esta ley; para pagar al CENECOOP hasta el dos y medio por ciento $(2,5 \%)$ de los excedentes líquidos al cierre de cada ejercicio económico, porcentaje éste que, según el criterio del consejo de administración de cada cooperativa, podrá pagarse de la reserva de educación».

La interpretación pretendía identificar el destinatario de una contribución parafiscal, pues se ha generado una duda respecto a quién se refiere el artículo 80 de la Ley de Asociaciones Cooperativas, o sea el CENECOOP R.L. Este proyecto obtuvo dictamen afirmativo de mayoría 25 de noviembre de 2008.

\section{Iniciativas que reforman indirectamente la legislación y la vida del cooperativismo nacional}

Por otra parte, también en la vida legislativa, en la corriente de los proyectos de ley, encontramos muchas iniciativas dirigidas a fortalecer en forma indirecta la participación del cooperativismo, en el país. Para entender un poco, el entorno nacional e internacional que influye en la vida del cooperativismo nacional, procedemos a resumir las iniciativas más sobresalientes al respecto.

\footnotetext{
${ }^{3}$ Ver expediente N. 17.156, ST.325-2008 J, nov. 2008.
} 


\subsection{Proyecto de ley de régimen jurídico del Banco nacional de desarrollo, expediente número 16054, presentado por varios diputados, 1 de noviembre de 2005}

Este proyecto encontraba sus bases en la necesidad sentida por sus proponentes, de poner un contrapeso financiero del sector de economía social, frente a la introducción del Tratado de libre comercio. El punto de partida era la definición clara de la solidaridad para garantizar el acceso democrático a la libre empresa; el acceso democrático a las finanzas; la actitud solidaria de una nación con sus miembros de menos recursos que incursionan en la producción nacional da lugar a la propuesta de existencia de un Banco de Desarrollo como una vía de acceso a la producción para muchos costarricenses.

Comprendidas las pequeñas y medianas cooperativas dentro de los pequeños y medianos empresarios (sector llamado PYMES), se buscaba ofrecerles una manera de encontrar una puerta abierta a sus aspiraciones de producir y construir una empresa, con acceso a créditos diferenciados con intereses realmente bajos y con plazos de medianos a largos, pueden convertirse en un instrumento que realmente proporcione oportunidades a las clases más pobres para desarrollar su propia industria o empresa.

Es el título segundo, donde se proponía la creación del Sistema Nacional de Banca de Desarrollo y Fomento (SNBDF) y se indica el texto que dentro de las múltiples entidades que lo integraran están consideradas las cooperativas que se dediquen o tengan como objeto social principal la realización de actividades de banca de desarrollo y fomento.

Este proyecto pasó a estudio e informe de la Comisión Permanente de Asuntos Económicos.

2.2. Proyecto de reforma N. 16447 a la Ley de participación de las cooperativas de electrificación rural y de las empresas de servicios públicos municipales en el desarrollo nacional, N. 8345, Expediente $\mathrm{N}^{\circ}{ }^{\circ}$ 15.248, 29 de mayo de 2003. Este proyecto pasó a estudio e informe de la Comisión Permanente de Gobierno y Administración

El objetivo era ampliar el trabajo realizado por las cuatro cooperativas eléctricas, que operan desde 1964, permitiendo un impulso significativo a las zonas de Guanacaste, San Carlos, Zarcero y Los Santos para que pasaran de ser simples compradores y distribuidores de la energía del 
Instituto Nacional de Electricidad (ICE), sino que por medio de la reforma a la ley viene a dotar a estos organismos del andamiaje técnico-jurídico para poder ingresar y competir en el mercado con aciertos empresariales en beneficio del interés local y nacional.

Cabe llamar la atención sobre la reacción de intereses que pesaban ya por la futura aceptación del Tratado de Libre Comercio con Estados Unidos, dentro del cual se incorporó la privatización de los servicios eléctricos y que hacían más difícil la ampliación de estos servicios dentro de empresas de economía social, como son las cooperativas, por ello es interesante conocer que el dictamen fue unánime y negativo el 10 de octubre de 2006.

2.3. Proyecto de Ley de democratización de la economía costarricense y lucha contra la pobreza mediante la activación económica. Expediente N. ${ }^{\circ} 15.372,26$ de agosto de 2003. Este proyecto pasó a estudio e informe de la Comisión Permanente de Asuntos Sociales

2.4. Proyecto de ley que autoriza la constitución de la cooperativa para trabajadores cesantes de la empresa privada. Expediente N. ${ }^{\circ} 16.553,2007$ presentado por Diputado Jorge Eduardo Sánchez. Este proyecto pasó a estudio e informe de la Comisión Permanente de Asuntos Sociales

El proyecto buscaba autorizar al Instituto de Fomento Cooperativo (Infocoop) para destinar de sus recursos propios o a adquirir un crédito nacional o internacional, para realizar la constitución de una cooperativa que se dedique al procesamiento y comercialización de aluminio o cualquier otro tipo de material metálico. Cooperativa integrada al menos con las personas que quederan cesantes de la empresa Aluminios Nacionales, S.A. (Alunasa), o cualquier otra persona que cuente con los requisitos que establezca el Infocoop para integrar esta nueva cooperativa

2.5. Adición de un artículo 185 bis a la LAC. EXPEDIENTE N. ${ }^{\circ} 15.854$, presentado por diputado Guido Vega Molina, 19 de abril de 2005. Este proyecto pasó a estudio e informe de la Comisión Permanente de Asuntos Sociales

El objetivo perseguido fue que el Instituto Nacional de Fomento Cooperativo (INFOCOOP), girara cada año de su superávit un $10 \%$ a fa- 
vor del Consejo Nacional de Cooperativas (CONACOOP) y del Centro de Estudios y Capacitación (CENECOOP), como fuente de financiamiento para los programas de educación, formación, capacitación y transferencia de tecnología al movimiento cooperativo, así como para apoyar los gastos administrativos y logísticos.

\subsection{Proyecto para promulgar una ley de Promoción para las} cooperativas de trabajo asociado o de autogestión. Expediente N. ${ }^{\circ} 16.482,6$ de diciembre de 2006

Este proyecto pasó a estudio e informe de la Comisión Permanente de Asuntos Sociales.

El objetivo del proyecto era reformar una serie de artículos de la Ley N. ${ }^{\circ} 4179$, y permitir a las cooperativas de trabajo asociado o autogestión, actuar en una manera organizativa y empresarial ante las nuevas condiciones que presenta el entorno, a la vez se fortalecen instrumentos de financiamiento que puedan consolidar esta forma de organización desde su incubación hasta la maduración.

Y dotar de personería jurídica instrumental a la Comisión Permanente de Cooperativas de Autogestión que es su organismo de integración creado por ley, que hasta el momento adolece de tal instrumento.

\subsection{Reforma parcial a la LAC para el fortalecimiento de las} organizaciones de Economía Social costarricense, expediente N. ${ }^{\circ}$ 16.447, propuesto por el Partido Acción Ciudadana, partido político relativamente nuevo en el marco político del país, con apenas ocho años de existencia y que detenta el segundo lugar en la Asamblea Legislativa, encontramos en un paquete de once proyectos de reforma a leyes específica, se propuso en el punto octavo: un fortalecimiento de las organizaciones de la economía social costarricense

Por medio de la conservación de las cooperativas, como parte del sistema estatal de fomento de éstas, bajo un régimen fiscal de no sujeción del acto cooperativo en materia de impuesto sobre la renta a empresas, en atención a su función social y a sus particulares características como entidad asociativa. También apertura a otras formas jurídicas de asociación para dar posibilidad a una mayor inclusión social, la creación de puestos de trabajo estables, de calidad y ensanchamiento del parque empresarial del país. 
También se proponía el refuerzo de las instituciones públicas de fomento y promoción del cooperativismo, de forma que sus recursos puedan utilizarse efectivamente en el financiamiento, asistencia técnica, capacitación, supervisión y promoción de las cooperativas y, particularmente, de la micro y pequeña empresa cooperativa.

La creación de un sistema nacional de formación humana y de transferencia de conocimientos para el impulso de la actividad productiva y de la oportuna atención, de las necesidades en este campo, de las micro, pequeñas y medianas empresas.

\section{La necesaria reforma a la ley de organizaciones cooperativas}

Desde nuestro ingreso al Movimiento Cooperativo nacional, en 1982 hemos participado en múltiples actividades, ya fueran con cooperativistas o bien, con abogados expertos en Derecho Cooperativo, con el objetivo de reformar y adecuar la ley cooperativa a las nuevas tareas que se imponen mundialmente a este tipo organizaciones.

En el año 2003 se impulsó con mucho avance en el torrente legislativo una reforma integral de la ley vigente, y hasta se dejó de lado el nombre de asociación cooperativa para reconocer una naturaleza jurídica más definida para este tipo de organización, denominándola únicamente COOPERATIVA. Esto fue importante porque en Costa Rica las asociaciones no tienen fin de lucro para sus miembros, mientras que en la cooperativa hay que buscar múltiples explicaciones para sustentar que los asociados obtienen ganancias de su actividad dentro y con la empresa cooperativa.

La temática que tantos autores latinoamericanos y europeos han tratado en sus múltiples intervenciones en trabajos de reformar a la legislación latinoamericana, llámese Proyecto de Ley marco para cooperativas de América, impulsado por la Organización de cooperativas de América y de reciente revisión por la Alianza cooperativa internacional para las Américas, por medio del Grupo Multidisciplinario Cooperativo ${ }^{4}$; Recomendación 193 de 2002 de la OIT sobre la Promoción de las Cooperativas, la minuciosa revisión realizada por la Alianza Cooperativa Internacional con frutos expuestos en Manchester, Inglaterra en 1995; la Recomendación 193 de 2002 de la OIT sobre la Promoción de las Cooperativas $^{5}$, y la influencia de las iniciativas a nivel regional que se

${ }^{4}$ Grupo integrado por el proyecto INCIDENCIAS de la ACI para las Américas, dirigido por el Lic. Alberto Mora y formado por su Coordinador Dr. Dante Cracogna, Dr. Belisario Guarín y Dra. Roxana Sánchez Boza, nace en el año 2007. 
han venido aprobando en los países del Cono Sur, indudablemente que son fuente necesaria para cualquier planteamiento de reforma integral o parcial de la actual ley cooperativa costarricense.

Una de las leyes que más han influido en las discusiones e incorporación de normativa novedosa a la actual Ley de asociaciones cooperativas, vigente en Costa Rica, ha sido la Ley de cooperativas del país vasco, región de España con la cual nuestro movimiento cooperativo ha mantenido una estrecha relación, en aras de desarrollar el cooperativismo de ambas partes del mundo, comprender mejor las herramientas que han favorecido el desarrollo de la economía social en España y buscar alianzas para impulsar su evolución positiva en nuestro país.

Siguiendo la tónica de la exposición hacemos una obligada referencia a un proyecto de LEY GENERAL DE LAS COOPERATIVAS tramitado en la Asamblea Legislativa en el año 2001, bajo el expediente N. ${ }^{\circ}$ 14.191. Este proyecto fue gestado desde el año 1998 por una comisión interna del Movimiento Cooperativo que reúne muchas de las iniciativas presentadas por grupos de cooperativistas, participantes en los Congresos Cooperativos o Talleres de legislación así como abogados y abogadas identificados con los principios y valores cooperativos.

Como habíamos indicado tuvo un avance significativo en la corriente legislativa y se le dio un dictamen favorable de la Comisión mixta, basado en dos dictámenes técnicos. El dictamen fue unánime y afirmativo pero no logró su aprobación como ley de la República.

\section{La Ley Marco para las cooperativas de América y nuestras propuestas de reforma al marco jurídico cooperativo de Costa Rica}

Como antecedente es importante hacer mención a la influencia de la propuesta de Ley marco para las cooperativas de América, impulsada por la Organización de Cooperativas de América y rescatada por la Alianza Internacional Cooperativa para las Américas, en el año 2005.

De un breve análisis cuantitativo sobre la inserción de las propuestas de ese proyecto, elaboramos el cuadro que sigue con muchas de las novedades que deberían ser incluidas en la legislación costarricense, tomadas tanto de la letra de la Ley marco, como de nuestra experiencia. El cuadro fue elaborado tomando en cuenta los países y los artículos de su propia legislación que incorporaban al año 2007, parte de la Ley marco para cooperativas, se distribuye en dos partes, la primera es el cuadro, la segunda es la lista de propuestas de reforma incluidas en la legislación centroamericana y un agregado de nuestra parte como sugerencia de reforma: 


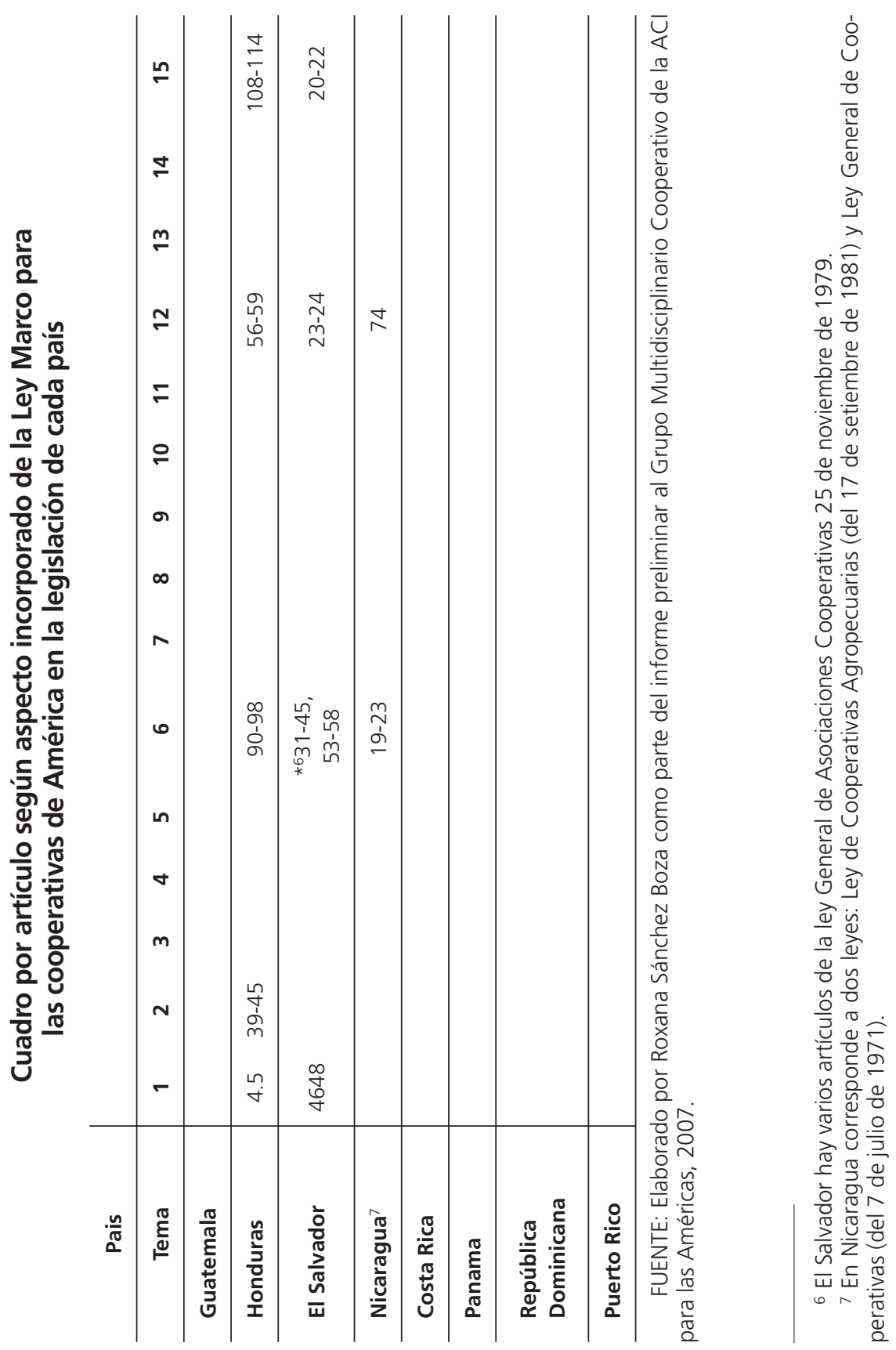




\section{Control de temas novedosos tanto Ley Marco como propuestos}

1. Incorporación del acto cooperativo.

2. Ubicación del Registro de cooperativas.

3. Posibilidad de aceptar "socios inversores» o sea tenedores de certificados que no sean usuarios de los servicios de la cooperativa, como forma de posibilitar el incremento del capital.

4. En caso afirmativo al punto anterior, considerar posible participación minoritaria de tales inversores en el consejo de administración.

5. Regulación de organizaciones «pre-cooperativas», es decir entidades de características simplificadas que pudieran posteriormente transformarse en cooperativas.

6. Separación de las funciones públicas relacionadas con las cooperativas en distintos organismos: registro; supervisión; promoción.

7. Empleo de métodos alternativos de solución de conflictos en las cooperativas (mediación, arbitraje), sin perjuicio de poder acceder a la justicia.

8. Participación equitativa de género

9. Balance y auditoría sociales

10. Absentismo del asociado (a) y falta de representatividad.

11. Control en pago de dietas

12. Exoneración de impuestos o regimenes impositivos especiales

13. Incorporación de la juventud

14. Atención a socios y socias adultos mayores

15. Cultura registral en protección de terceros y a los mismos miembros.

\section{Normativa de proteccion al consumidor.}

* Los temas en negrita son propuestos por Roxana Sánchez Boza.

Como se puede observar de la anterior lista, un grupo de abogados interesados en el tema de las reformas legislativas, tenemos elegidos un grupo de aspectos como base de una nueva ley de cooperativas. Exponemos nuestras razones que fundamentan la normativa por incorporar: 
4.1. La incorporación dentro del texto legal de los Valores y Principios cooperativos como forma de dar forma legal a la Declaración sobre la Identidad Cooperativa, adoptada por la Asamblea General de la Alianza Cooperativa Internacional, en setiembre de 1995, es uno de los aspectos básicos que permitirían una interpretación e integración de la normativa cooperativa con base en tales valores y principios de aceptación mundial y como faro en la multiplicidad de actividades de las cooperativas, que en algún momento pueden tener desviaciones o confusiones en la forma de ejecutar los principios de solidaridad, mutualidad, cooperación cuando entran en contacto con el resto del mercado, cuya exigencia fundamental es la ganancia sin la consideración de tales principios como idea fuerza de su actividad

En este espacio también es relevante considerar el voto diferenciado para las cooperativas de base y las segundo y ulterior grado, en el tanto que el principio democrático una persona un voto, a veces no puede operar cuando se dan relaciones entre entes cooperativos pequeños en su capital cooperativo y por lo tanto volumen de operaciones así como cantidad de miembros, frente a las grandes cooperativas que participan en entes cooperativos sean federaciones o uniones, donde esos tres aspectos pueden pesar en las decisiones y dirección de la actividad de esas organizaciones.

La toma de partido en cuanto a la vida de la organización cooperativa de segundo a ulterior grado, que debe beneficiar en primera instancia a la entidad representada encuentra muchas veces una clara contradicción de intereses entre la gran cooperativa y la pequeña, cuya solución se ha encontrado en el trato diferenciado del voto en cuanto a número de socios, volumen de operaciones y peso del capital cooperativo para decidir la distribución de los votos.

\subsection{Acto cooperativo, Derecho cooperativo y relaciones con terceros}

Dado que desde el proyecto de Ley Marco para cooperativas se venía insistiendo en la necesidad de definir mejor la naturaleza de las cooperativas, es importante considerar la definición del acto cooperativo y enmarcarlo dentro del Derecho cooperativo, lo cual nos ofrece otras herramientas para interpretar la naturaleza de los actos con terceros que pueden ser de relaciones comerciales de consumo: venta de productos, de servicios o alianzas comerciales y su separación con los actos cooperativos.

El proyecto de Ley marco para cooperativas considera como acto cooperativo, aquel acto realizado entre cooperativistas, entre éstos y las 
organizaciones cooperativas o entre éstas dirigido a satisfacer el objetivo social y económico cooperativo.

\subsubsection{INGRESOS PROVENIENTES DE ACTIVIDAD CON TERCEROS}

Un acto de una cooperativa con no socios, sale del ámbito cooperativo, es una actividad de la cooperativa con un tercero.

Los terceros aprovechan la actividad cooperativa, en el tanto que está organizada para ofrecer un producto o servicio, creado bajo valores y Principios cooperativos, por lo cual el producto final resulta más conveniente para el tercero contratante con la misma, si la cooperativa ha basado su actividad en la ayuda mutua, la cooperación, la solidaridad.

También desde el punto de vista de la obtención de capital para el desarrollo de la cooperativa, nos encontramos la participación de empresas no cooperativas, lo cual abre espacios a ambas empresas que pueden dar resultados dudosos para la economía cooperativista, tentada por el lucro mercantil y el traslado de ventajas reconocidas a las empresas cooperativas a empresas fuera de ese sector, que no funciona con los límites establecidos para las primeras, como por ejemplo, en Costa Rica, las cooperativas no declaran impuesto de la renta como tales, sin embargo, sus socios y socias lo hacen pero con límite ventajoso, pues tiene un tope del 5\% sobre los excedentes.

Nuestra posición al respecto es definir mejor el tipo de actividad que realiza las cooperativas que tienen más posibilidad de ofrecer sus productos y servicios a terceros. Eso se lograría mediante una mejor calificación de los servicios bajo un sello de solidaridad cooperativa, entendiendo que los ingresos o ganancias que provengan del servicio prestado a la comunidad donde se desarrolla la cooperativa o al país, tendrá la oportunidad de no declarar renta sobre tales ingresos y trasladar parte de los mismos a sus miembros.

El derecho de los cooperativistas a gozar de los beneficios por ingresos provenientes de la actividad con terceros, lo fundamento en el hecho cooperativo, es si no existiera la cooperativa, formada por aquellos(as) socios(as), los productos y los servicios de la misma no podrían ser ofrecidos a los terceros, y podemos ver que el vínculo de esas ganancias es claro con la cooperativa y los socios y socias tienen derecho a participar en sus excedentes de un porcentaje de los mismos. Mientras que otro porcentaje se puede destinar a reforzar la investigación y la formación del Movimiento Cooperativo. 


\subsubsection{LA PARTICIPACIÓN DEL SOCIO COLABORADOR}

Otro planteamiento existente en algunas propuestas de reforma a la ley de cooperativas es la introducción de la figura del socio colaborador o socio inversor. Su existencia nos lleva a una fractura en el principio de participación democrática en una cooperativa, pues se prevén limitaciones en la asamblea y el número de integración en el órgano social de administración, que se propone en un máximo de un tercio de los miembros del mismo.

Sin embargo, en cuanto a las ganancias, lo más interesante es tener en cuenta la oposición de intereses, el interés del socio colaborador será obtener el máximo de ganancia y el interés del ente cooperativo es obtener el máximo de satisfacción del servicio cooperativo para sus socios.

Frente a la anterior disyuntiva, consideramos oportuno dejar incólume la integración de las cooperativas, y establecer otro tipo de relaciones, fuera de la cooperativa con estos empresarios (as) por medio de otro tipo de asociaciones empresariales que beneficien a ambas partes sin desnaturalizar la actividad propia de cada uno de estos entes.

\subsection{Revisión del número socios fundadores de cooperativas, estructura organizativa más ágil, reducción de órganos sociales}

Hasta el presente en Costa Rica se ha hecho la diferencia del número de socios (as) necesario para el nacimiento de una cooperativa, a partir de la consideración del modelo autogestionario y el resto de cooperativas, donde al primero se le hizo la concesión en el año 1982, de rebajar el número mínimo a 12 miembros y en el resto de cooperativas se conservó el número de 20 miembros.

El tema ha sido muy discutido en el ámbito cooperativo nacional, y se han hechos propuestas de rebajar a cuatro miembros el número necesario para constituir una cooperativa. Mientras otro sector del cooperativismo nacional mantiene su posición por el número existente.

Nuestra posición es disminuir el número de veinte a cuatro miembros de acuerdo con la estructura de la cooperativa, como ente económico-social, en donde la toma de decisiones debe ser ágil, rápida y eficaz. La experiencia es que ante un número mayor de personas, el cumplimiento del objetivo cooperativo se desvía en la búsqueda de puestos directivos, el ejercicio de los derechos parapolíticos pesa más que la inversión de recursos en el desarrollo de la cooperativa en su campo económico-financiero. A veces, hemos asistido a asambleas anuales que toman una jornada diaria, de las siete de la mañana a las ocho de 
la noche, y el mayor tiempo se destina a las votaciones para elegir a los directivos de los órganos sociales.

Lo anterior lleva también a buscar una estructura organizativa más ligera, para aligerar la toma de decisiones, menos cuerpos directivos y menos luchas políticas, más eficiencia en la obtención de los fines y objetivos económico-sociales de las cooperativas.

Tanto en otros Movimientos Cooperativos, como el español así como otros entes de la economía social, como la introducción en los años 90 de las sociedades anónimas laborales, el número se ha reducido a cuatro miembros. De esa situación surgen dos desventajas visibles para las cooperativas: a) se requieren más socios(as) para su nacimiento, se deben nombrar más integrantes de cuerpos directivos y b) las otras entidades se multiplican y aprovechan los beneficios de participación político-económica que ofrece el sistema de mercado nacional cuando la toma de decisión es ágil y acorde a la velocidad de su desarrollo.

\subsection{Del registro de cooperativas}

Un aspecto que ha tomado recientemente gran importancia es la necesidad de instituir un Registro de Cooperativas, organizado bajo los principios registrales y la técnica jurídica registral, en el tanto que hasta ahora han funcionado dos registros, uno ubicado en el Departamento de Organizaciones Sociales del Ministerio de Trabajo, que inscribe seis tipos diferentes de organizaciones de economía social, reguladas por tantas leyes independientes como su número los hacen nacer.

El otro registro se ubica en el Departamento de Cooperativas del Ministerio de Educación, para las cooperativas infantiles, escolares y juveniles. Este registro no es reconocido por la LAC, para efectos del nacimiento de las cooperativas.

El reciente censo cooperativo, impulsado por el CONSEJO NACIONAL DE COOPERATIVAS y el INFOCOOP informó en forma fehaciente acerca de la situación de muchas cooperativas existentes únicamente en los documentos, de ahí que estamos enfrentando un proceso de depuración de las inscripciones de muchas cooperativas que no funcionan o tienen documentos pendientes de inscribir, entre los cuales existen importantes reformas a los estatutos. Tales situaciones indudablemente son fuente de inseguridad jurídica y de poca claridad para demostrar cuáles entes cooperativos pueden participar en otros entes de la Economía Social.

Por ejemplo, para participar en la Asamblea de Trabajadores y Trabajadoras del Banco Popular y de Desarrollo Comunal, seno de decisiones para integrar la Junta Directiva del mismo; Juntas de crédito, juntas 
directivas de las sociedades anónimas del Banco, el Directorio que es otro órgano del mismo, se debe demostrar que se tienen dos requisitos exigidos por la Ley orgánica del Banco:

- ser cooperativista, lo cual se demuestra, en el caso de la participación cooperativa, por medio de las listas de asociados(as) que forman las cooperativas y deben ser informadas al Registro de Cooperativas del Departamento de organizaciones sociales mencionado.

- ser trabajador en una obligación laboral subordinada y cotizante por más de un año para el mismo Banco.

Como vemos además de ofrecer información sobre la existencia de las cooperativas y cuál es su régimen jurídico específico, por medio de la inscripción de sus estatutos y quién ostenta la representación. También se obtiene información para controlar en forma transparente la participación del Movimiento Cooperativo en un ente que es el brazo financiero del Sector de Economía Social del país.

4.5. Responsabilidad social de los miembros de los organos sociales. Representacion de la cooperativa. Derecho de informacion. Recursos y periodo de prescripcion

Por el momento, existe una responsabilidad civil general en relación con los actos cooperativos realizados en detrimento de las cooperativas, de sus miembros o de terceros, por parte de los socios o socias elegidos en cuerpos directivos de las mismas.

Consideramos pertinente la introducción de la normativa necesaria para definir las faltas leves, menos leves y graves en que pueden incurrir los miembros de los órganos sociales y sus consecuencias en relación con la responsabilidad de su actuación, como una forma de protección de los mismos miembros de las cooperativas.

Por otro lado, en forma excepcional, las cooperativas en Costa Rica y entes de grado ulterior, han tenido como representante legal al gerente y la actividad del Consejo de Administración queda relegada al interior de la cooperativa, y el Presidente de ese órgano no participa en forma activa y en contrataciones importantes, fuera de la cooperativa. Por eso, aprobamos la propuesta de muchos cooperativistas de ubicar la representación legal judicial y extrajudicial de la cooperativa, en la persona del Presidente del Consejo de administración, lo cual puede ser acompañada de una decisión del mismo Presidente o del consejo de delegar parte de las facultades de representación del Presidente, en el gerente. 
4.5. Reformas a la normativa de cooperativas de autogestión o trabajo asociado

Dentro del proyecto denominado reforma parcial a la Ley de asociaciones cooperativas y creación del INFOCOOP N. 4179 y sus reformas para el fortalecimiento de las organizaciones de economía social costarricense, se dan varias propuestas que compartimos porque el régimen dado a este tipo de cooperativas es totalmente desigual frente al resto de organizaciones cooperativas del país.

En esta reforma se busca reducir el número de socios fundadores a cinco, el reconocimiento de la personería instrumental para la Comisión Permanente de Cooperativas de Autogestión como órgano adscrito al Consejo nacional de cooperativas, con personería jurídica instrumental junto con la dotación de mayores recursos.

Y se hace una revisión obligada de la cantidad de reservas previstas y de rebajar antes de aprobar los excedentes a distribuir en el año fiscal de las cooperativas. Obligada porque es excesiva la cantidad de reservas, lo ha hecho que este tipo de cooperativas contribuyan en mayor grado con la evolución del Movimiento cooperativo nacional.

\subsection{Incorporación de la mujer cooperativista a en los espacios de decisión política del cooperativismo}

El ordenamiento jurídico costarricense fue impactado positivamente por la aprobación de la ley ... que estableció la paridad y la equidad de la participación de las mujeres miembros de diferentes entidades del sector de economía social, en la Asamblea de trabajadores y trabajadoras, en el Directorio, en las Sociedades anónimas, las Juntas de Crédito del Banco Popular y de Desarrollo Comunal.

Sin embargo, la bola de nieve se detuvo hace años, y la influencia de tal iniciativa llevada a ley, quedó sin desarrollo en otros ámbitos de ese importante sector.

Es por lo anterior, que en algún momento de nuestra participación en actividades políticas del Movimiento Cooperativo nacional, hicimos una propuesta de reforma a la ley cooperativa, en busca de ampliar las posibilidades en la toma de decisión, para este importante grupo de ese sector y por ello, nos permitimos transcribirla, considerando que el órgano protagonista de la misma es el Comité nacional de la mujer cooperativista: 


\section{Propuesta de reforma a la Ley de cooperativas}

1. El Comité nacional de la mujer cooperativista considera que se encuentra en el momento oportuno para acceder directamente a un puesto de propiedad y a otro de suplencia en el Plenario del CONACOOP, para ello propone el siguiente artículo:

Art.... El Comité nacional de la mujer cooperativista como organismo de integración de representación y defensa tendrá un puesto permanente con voz y voto en el seno del Plenario del CONACOOP, que será ejercido por una representante propietaria y su suplente y quienes serán elegidas de conformidad con el reglamento del comité y regirá por el tiempo que determine ese reglamento para las representaciones.

2. Asimismo el Comité considera necesario que el movimiento cooperativo avance en el reconocimiento de nuevas formas de cooperación, regidas por los Principios y valores de la Alianza Cooperativa Internacional y propone una reforma al registro de organismos cooperativos, con la siguiente letra:

Art... El Registro de organizaciones cooperativas inscribirá:

- Cooperativas de base

- Organismos cooperativos de integración

- Entidades de integración que se constituyan bajo los Principios y valores de la $\mathrm{ACl}$.

Presentado por Roxana Sánchez Boza

24-2-99 al Comité nacional de la mujer cooperativista. 